\title{
Reiki Therapy
}

National Cancer Institute

\section{Source}

National Cancer Institute. Reiki Therapy. NCI Thesaurus. Code C15728.

An alternative medical practice. The practitioners of reiki believe that health and disease are a matter of the life force being disrupted. Reiki healers claim to channel reiki into "diseased" individuals for "rebalancing." (from Skeptic's Dictionary) 